ISSN 1981-416X

Licenciado sob uma Licença Creative Commons

\title{
Educação online e educação aberta: avanços, lacunas e desafios
}

\author{
Online education and open education: \\ advances, gaps and challenges
}

\section{Educación online y educación abierta: avances, lagunas y desafios}

\section{Jacques de Lima Ferreira ${ }^{[a][b]}$, Ygor Corrêa ${ }^{[c]^{*}}$}

\author{
[a] Universidade Positivo (UP), Curitiba, PR, Brasil \\ [b] Universidade Federal do Paraná (UFPR), Curitiba, PR, Brasil \\ [c] Centro Universitário Ritter dos Reis (UniRitter), Porto Alegre, RS, Brasil
}

\section{Resumo}

Este artigo apresenta o estado da arte da Educação online e da Educação aberta, a partir do mapeamento e da análise de pesquisas científicas, dissertações e teses, durante o período de 1996 a 2017. Este realiza um mapeamento e analisa as contribuições e as implicações presentes em pesquisas acadêmicas, possibilitando uma melhor compreensão do que essas investigações têm revelado. Esta pesquisa apresenta uma abordagem qualitativa, descritiva e interpretativa e faz uso do software Atlas Ti, para fins de operacionalização da análise de dados, assim como apoia-se na técnica de Análise de conteúdo. Enquanto

*JLF: Doutor em Educação, e-mail: drjacqueslima@hotmail.com

YC: Doutor em Informática na Educação, e-mail: correaygorprof@gmail.com 
objeto de estudo foram identificadas 88 teses e 256 dissertações, que foram coletadas na Biblioteca Digital Brasileira de teses e dissertações. A análise de dados permitiu identificar que em relação à Educação Online e à Educação Aberta as pesquisas têm enfatizado a importância da flexibilização da Educação para o processo de aprendizagem, bem como a utilização de diferentes recursos didáticos e tecnológicos, enquanto ferramentas que permitem o uso de metodologias interativas. Identificou-se também que a desmotivação dos participantes está associada à metodologia de ensino adotada.

Palavras-chave: Estado do Arte. Educação Online. Educação Aberta.

\section{Abstract}

This paper presents the state of art of Online education and Open education, considering the mapping and the analysis of scientific researches, dissertations, and theses, during the period from 1996 to 2017. This article intends to map and analyze patents and ways of doing academic research to better understand what these investigations have revealed. This research has a descriptive and interpretative qualitative approach and makes use of the Atlas Ti software, for the purposes of data analysis operation, as well as based on the technique of Content Analysis. As a study object, 88 theses and 256 dissertations were identified, which were collected from the Brazilian Digital Library of Theses and Dissertations. The data analysis allowed to identify that in relation to Online Education and Open Education the researches have emphasized the importance of the flexibility of Education for the learning process, as well as the use of different didactic and technological resources, as tools that allow the use of interactive methodologies. It was also identified that the demotivation of the participants is associated with the teaching methodology adopted.

Keywords: State of Art. Online Education. Open Education. 


\section{Resumen}

Este artículo presenta el estado del arte de la Educación en línea y Educación Abierta, a partir del mapeo y del análisis de investigaciones cientificas, disertaciones y tesis, durante el período de 1996 a 2017, con el objetivo de mapear y analizar las contribuciones y las implicaciones presentes en investigaciones académicas para comprender mejor lo que esas investigaciones han revelado. Esta investigación tiene un enfoque cualitativo, descriptivo e interpretativo y hace uso del software Atlas Ti, para fines de operacionalización del análisis de datos, así como se apoya en la técnica de Análisis de Contenido. En cuanto objeto de estudio se identificaron 88 tesis y 256 disertaciones, que fueron recogidas en la Biblioteca Digital Brasileña de Tesis y Disertaciones. El análisis de datos permitió identificar que en relación a la Educación Online y Educación Abierta las encuestas han enfatizado la importancia de la flexibilización de la Educación para el proceso de aprendizaje, así como la utilización de diferentes recursos didácticos y tecnológicos, como herramientas que permiten el uso de metodologías interactiva. Se identificó también que la desmotivación de los participantes está asociada a la metodología de enseñanza adoptada.

Palabras clave: Estado del Arte. Educación en línea. Educación Abierta.

\section{Introdução}

O crescente avanço e a propagação do uso das Tecnologias da Informação e Comunicação (TIC) possibilitaram que novas perspectivas para a Educação fossem alcançadas, em especial, na Educação a Distância. A Educação a Distância, sendo uma modalidade de Educação, permite que informações possam se transformar em conhecimento quando os alunos utilizam mídias e recursos tecnológicos para aprender. Além disso, em seus diferentes formatos, possibilita o acesso à Educação Online, Aberta, Híbrida, Massiva, dentre outras. Frente a esses diferentes formatos para a aprendizagem, tem-se a Educação Online e a Educação Aberta, que, atualmente, proporcionam processos de ensino e aprendizagem em diversos contextos interativos. 
Diante da oferta dessas modalidades, este estudo, enquanto pesquisa qualitativa descritiva e interpretativa, do tipo estado da arte, tem por objetivo mapear e analisar as contribuições e as implicações presentes em pesquisas científicas, dissertações e teses, durante o período de 1996 a 2017. Deste modo, o estudo adota postulações de pesquisadores da área (SILVA, 2009; SANTOS, 2009) para apresentar e entender o conceito de Educação Online, assim como quanto à Educação Aberta (AIRES, 2016; OKADA, 2009).

Seguindo a perspectiva de Romanowski e Ens (2006) e de Vosgerau e Romanowski (2014), no que refere-se a uma pesquisa do tipo estado da arte, infere-se que os apontamentos resultantes deste estudo podem contribuir com o campo teórico investigado, a identificação de aportes significativos da teoria e prática pedagógica, o apontamento de restrições no campo de pesquisa, a elucidação de lacunas e o evidenciamento de práticas inovadoras. Tendo em vista os itens tomados a partir das postulações de Romanowski e Ens (2006) e de Vosgerau e Romanowski (2014), acredita-se que os resultados dessa pesquisa possam beneficiar pesquisadores e alunos do Stricto Sensu, na medida em que se torne possível interpretar de forma mais pontual as duas modalidades de Educação e suas particularidades relativas ao processo de ensino e aprendizagem.

Depreende-se, assim, que este estudo pode permitir a sistematização das produções realizadas no âmbito do Stricto Sensu, bem como, a identificação de progressões conceituais e características específicas provenientes das produções científicas realizadas durante o período de 1996 a 2017. Para tanto, neste estudo foram analisadas 256 dissertações e 88 teses, coletadas na plataforma digital do Instituto Brasileiro de Informação em Ciência e Tecnologia (IBICT) na Biblioteca Digital Brasileira de Teses e Dissertações (BDTD). A análise de dados foi conduzida com o auxílio do software Atlas Ti e para fins de operacionalização da Análise de Conteúdo (AC), utilizou-se a técnica proposta por Bardin (2011). Na próxima seção são apresentadas postulações teóricas acerca dos conceitos de Educação Online e de Educação Aberta, assim como particularidades. 


\section{Educação online e Educação aberta}

A Educação a Distância caracteriza-se pela dinâmica de utilizar meios e tecnologias para mediar o processo de ensino e aprendizagem onde professores e alunos encontram-se em diferentes localizações geográficas. Esta modalidade de educação tem a função de ensinar e aprender, sem que docentes e discentes estejam ao mesmo tempo em um local determinado, ou seja, podendo ser de modo assíncrono. Embora não seja uma modalidade educacional recente, a Educação a Distância vem ganhando proporções significativas diante do ensino presencial à medida que o progresso das tecnologias favorece esta abordagem que acontece em diferentes formatos como: E-learning, Blended Learning, Online, Mobile Learning, Aberta, entre outros. Esses formatos, por sua vez, visam atender as diferentes características de aprendizagem.

Um destes formatos de Educação a Distância é a Educação Online, que pode ser definida "como o conjunto de ações de ensino-aprendizagem desenvolvidas por meio de meios telemáticos, como a Internet, a videoconferência e a teleconferência" (MORAN, 2012, p. 41). Em consonância com Moran (2012), Santos (2009) define a Educação Online como o "conjunto de ações de ensino-aprendizagem ou atos de currículo mediados por interfaces digitais que potencializam práticas comunicacionais interativas e hipertextuais" (SANTOS, 2009, p. 5663-5664). O autor acrescenta ainda que esta modalidade de ensino potencializa a democratização da informação, comunicação e a aprendizagem.

Desta maneira, entende-se que as tecnologias emergentes da atualidade mudam o perfil da aprendizagem diante da Educação Online quando envolvem o uso de diferentes TIC. Neste horizonte, encontram-se dispositivos móveis, enquanto tecnologias digitais, como celulares do tipo smartphones e tablets, que possibilitam o acesso ubíquo a unidades ou à totalidade dos cursos Online, em que uma série de componentes tecnológicos e de infraestrutura em rede são necessários para que ocorra o processo de ensino e aprendizagem, bem como professores-tutores capacitados para atuar no contexto digital de Educação a Distância. 
Neste cenário, para que ocorra qualquer tipo de formação Online é necessário que o aluno realize um processo de ambientação no contexto, havendo maior possibilidade do aluno utilizar de todos os recurso oferecidos, estes essenciais para a interação e a colaboração com os demais participantes de um curso/disciplina. Já o professor-tutor precisa estabelecer uma boa comunicação com os alunos, com vista a acompanhar e a mediar o processo de aprendizagem dos participantes de um ambiente virtual (KEARSLEY, 2011).

Relativo à Educação Aberta, o termo é utilizado atualmente no contexto dos Recursos Educacionais Abertos (REA) que permitem uma variedade de práticas educativas, popularizadas por meio do uso das tecnologias digitais. A Educação Aberta é aplicada em diferentes contextos, envolvendo diversas práticas, algumas bem atuais e outras não. Portanto, cabe ressaltar, contudo, que não é a utilização de um REA que constitui a Educação Aberta como tal, mas sim o modo como ela é planejada e executada. Desta forma, a Educação Aberta pode ser entendida de diversos modos, entretanto, sua real caracterização em todos os conceitos e aplicações necessita de um conjunto de práticas que dependem do contexto e do processo de ensino e aprendizagem para que venha a acontecer.

A Educação Aberta está relacionada à flexibilização do processo de ensino e aprendizagem compatível ao estilo de vida do aluno. No contexto virtual de Educação Aberta, o aluno precisa desenvolver-se a partir da sua autoaprendizagem, tendo o reconhecimento do curso/disciplina realizada de modo formal ou informal por meio de certificação opcional. Nesta modalidade educacional o aluno está isento de pagamento e de qualificações ou pré-requisitos, os quais poderiam configurar-se como barreiras para o acesso à Educação. Diante de sua caracterização, a Educação Aberta centra-se no desenvolvimento de práticas pedagógicas focadas no aluno, assim como na utilização de materiais criados pelos mesmos e, principalmente, pela acessibilidade à educação diante da diversidade humana (AIRES, 2016; OKADA, 2009). 
No entanto, este conceito é bastante abrangente, não havendo no cenário acadêmico uma única definição para a mesma justamente por ser um conjunto de práticas que evolui a partir das teorias, experiências e tecnologias utilizadas no campo da Educação.

$\mathrm{Na}$ educação superior, a Educação Aberta apresenta duas características fundamentais: a flexibilidade na admissão do acadêmico e o acesso a educação sem custo. A Universidade Aberta Britânica (Open University) foi fundada em 1969 e é um modelo mundial de Educação Aberta. No que diz respeito ao cenário brasileiro, esta abordagem de educação só surgiu a partir da criação da Universidade Aberta do Brasil em 2005, garantindo assim acesso gratuito à educação por meio da rede pública de Educação a Distância. O sistema de educação é aberto porque não existe barreira financeira para o ingresso e a permanência do aluno, isso porque a modalidade de Educação a Distância possibilita a oferta de educação superior nas regiões distantes das capitais (MOTA, FILHO, CASSIANO, 2009).

A Educação Aberta no ensino superior, de maneira geral, assemelha-se com a Educação Online, na medida em que busca centralizar o processo de ensino no aluno, porém diferencia-se ao ofertar um material de estudo específico que é elaborado para atender às necessidades de quem estuda sozinho e com linguagem dialógica, de maneira a motivar o aluno, disponibilizando o conteúdo em plataformas de aprendizagem virtual.

Após essa breve apresentação sobre os conceitos de Educação Online e Educação Aberta, como forma de situar ambas as modalidades em relação ao tipo de pesquisa em pauta neste estudo do tipo estado da arte, a seguir, apresenta-se o desenho metodológico da pesquisa realizada.

\section{Metodologia}

Esta é uma pesquisa de abordagem qualitativa, descritiva e interpretativa do tipo estado da arte, que se configura como uma investigação comumente adotada por pesquisadores de diferentes campos do 
conhecimento, especialmente na área da Educação. Este tipo de pesquisa permite interpretar os fenômenos educacionais em sua complexidade e variáveis, possibilitando o estabelecimento de uma interpretação empírica e detalhada acerca de sua fenomenologia, auxiliando na evidenciação e na compreensão de possíveis dilemas éticos, incertezas, paradoxos e ambiguidades.

Para tanto, tomando por base a pesquisa do tipo estado da arte, a partir das postulações de Romanowski e Ens (2006, p. 39), compreende-se que "[...] a análise do campo investigativo é fundamental neste tempo de intensas mudanças associadas aos avanços crescentes da ciência e da tecnologia". Na pesquisa do tipo Estado da Arte, “[...] o volume de produção pode ser grande, é usual, além de se estabelecer o campo de pesquisa e o tema pesquisado, definir um período de pesquisa, e estabelecer uma determinada fonte de dados" (VOSGERAU; ROMANOWSKI, 2014, p. 171).

No que se refere à identificação de pesquisas científicas, dissertações e teses, voltadas à Educação Online e à Educação Aberta, foram realizadas buscas online, por pesquisa científicas no Instituto Brasileiro de Informação em Ciência e Tecnologia (IBICT) na Biblioteca Digital Brasileira de Teses e Dissertações (BDTD), que serviram como instrumentos de coleta de dados. Relativo ao mapeamento e à identificação de teses e dissertações, esses procedimentos ocorreram via plataforma digital, quando da utilização da opção de busca avançada, recurso de filtragem disponibilizado pela própria plataforma, com a inserção das palavras-chave Educação Online e Educação Aberta. Convém ressaltar que essas duas palavras-chave estão indexadas no Thesaurus Brasileiro da Educação do Instituto Nacional de Estudos e Pesquisas Educacionais Anísio Teixeira (INEP).

Na continuidade do processo, o período de mapeamento da produção de teses e de dissertações foi delimitado ao período de 1996 a 2017, ou seja, 21 anos de pesquisa no campo da Educação Online e da Educação Aberta. A opção pelo ano inicial como sendo o de 1996 justifica-se pelo fato de que neste ano ocorreu a regulamentação da Educação a Distância 
no Brasil, tendo sido mencionada pela primeira vez, oficialmente, na Lei de Diretrizes e Bases da Educação Nacional (LDBEN), como modalidade pertencente à Educação. Após 1996, outros decretos, normativas e diretrizes foram sancionadas. Para além disso, cabe ressaltar que, a opção pela Biblioteca Digital Brasileira de Teses e Dissertações (BDTD) deve-se à possibilidade de realizar buscas a partir da delimitação do período de início e fim que se queira investigar. O banco digital de teses e dissertações da Coordenação de Aperfeiçoamento de Pessoal de Nível Superior (CAPES) não foi utilizado por estar, na época da coleta de dados, em manutenção.

Uma vez inseridas as palavras-chave e o período de produção, a plataforma da Biblioteca Digital Brasileira de Teses e Dissertações (BDTD) apresentou 619 pesquisas realizadas em nível de mestrado e doutorado (Acadêmico e Profissional). As 619 pesquisas apontadas pela plataforma digital foram submetidas a uma leitura crítica na íntegra, a fim de identificar e separar as dissertações e teses que comporiam ou não o corpus de pesquisa, caso efetivamente abordassem os temas Educação Online e Educação Aberta. Após esse processo, realizado pelos pesquisadores, o corpus de pesquisa restringiu-se a 256 dissertações (148 pesquisas sobre Educação Online e 108 sobre Educação Aberta) e a 88 teses (51 pesquisas sobre Educação Online e 37 sobre Educação Aberta), que tratam especificamente das duas modalidades de Educação pesquisadas, resultando em um total de 344 pesquisas acadêmicas ${ }^{1}$. Foram desconsideradas do corpus de análise 275 pesquisas, haja vista que essas não tratavam das modalidades em questão, mas de outros formatos de Educação a Distância, como, por exemplo, blended learning.

\footnotetext{
${ }^{1}$ Uma vez que se estava investigando a incidência de aspectos semelhantes tanto em pesquisas sobre Educação Online, quanto em Educação Aberta, inferiu-se como irrelevante analisar quantas dissertações e teses tratavam sobre cada modalidade. Essa tomada de posição está embasada na ideia de que o objetivo central é o de revelar o estado da arte das modalidades e não sua recorrência em diferentes níveis do Stricto Sensu.
} 
Para a análise dos dados foi realizada uma leitura das considerações finais das 256 dissertações e 88 teses, sendo relevante mencionar que a opção por realizar a análise dos dados por meio das considerações finais deve ao entendimento de que é nesta parte da pesquisa que o autor-pesquisador responde seu problema de pesquisa, além de contemplar seus objetivos apresentando conclusões a partir dos achados da investigação. Nas considerações finais das teses e dissertações que fazem parte do corpus de análise realizou-se a análise de conteúdo das mesmas na perspectiva de Bardin (2011), aplicando a técnica de Análise de Conteúdo (AC), bem como com o auxílio do software Atlas Ti, para fins de operacionalização de categorias de análise.

A técnica de AC é aplicada para analisar materiais em forma de textos, imagens, gravações, entre outros, sendo um método de análise conhecido nas Ciências Sociais, Psicologia e Educação. A AC é composta por um conjunto de técnicas de análise das comunicações que utiliza procedimentos sistemáticos e objetivos de descrição do conteúdo das mensagens (BARDIN, 2011). Por sua vez, a AC abrange diferentes etapas do processo de análise, sem constituir-se como uma técnica isolada de análise, assim cada pesquisador a aplica de acordo com a percepção que tem do fenômeno pesquisado. Metodologicamente, o presente estudo apoia-se nas postulações de Bardin (2011), depreendendo que as etapas da AC são constituídas por três fases, a saber: (a) pré-análise, (b) exploração do material e (c) tratamento dos resultados.

A pré-análise visa à organização, chamada também de leitura "flutuante", momento em que o pesquisador realiza a escolha dos documentos, a formulação das hipóteses, dos objetivos, da referenciação dos índices, da elaboração de indicadores e da preparação do material. Para Bardin (2011) a leitura "flutuante" corresponde ao primeiro contato com os documentos que serão submetidos à análise.

Já a fase de exploração do material compreende como "[...] a fase de análise propriamente dita, não é mais do que a aplicação sistemática das decisões tomadas. Quer se trate de procedimentos aplicados manualmente ou de operações efetuadas por computador [...]" 
(BARDIN, 2011, p. 131). Nesta etapa, a autora considera que ocorre a codificação, enquanto organização sistemática, que se realiza para posteriormente classificar e categorizar. A fase de categorização é o processo que permite que os códigos sejam agrupados, segregados ou reagrupados com o objetivo de consolidar um significado. Na visão de Bardin (2011) uma boa categorização apresenta qualidades como: exclusão, homogeneidade, pertinência, objetividade, fidelidade e a produtividade dos dados.

Por fim, a fase de tratamento dos resultados é aquela onde "[...] os resultados brutos são tratados de maneira a serem significativos e válidos" [...] e o pesquisador "[...] tendo à sua disposição resultados significativos e fiéis, pode então propor inferências e adiantar interpretações a propósito dos objetivos previsto ou que digam respeito a outras descobertas inesperadas" (BARDIN, 2011, p. 131). Na próxima seção, apresenta-se a análise de dados das 344 pesquisas arroladas como objeto de estudo desta pesquisa.

\section{Análise de dados e resultados}

Relativo à análise de dados das 256 dissertações e 88 teses, no total de 344 pesquisas acadêmicas que abordaram a temática Educação Online e Educação Aberta, a partir da perspectiva de Bardin (2011), quando da análise de conteúdo das considerações finais das dissertações e teses, conforme descritas na metodologia deste estudo. A seguir, descreve-se a aplicação de cada fase, preparação dos dados para análise (pré-análise), utilização do software Atlas Ti, codificação, categorização (exploração do material) e análise de conteúdo (tratamento dos resultados), a saber:

Fase 1 - Preparação dos dados para análise: todas as 344 pesquisas foram salvas em formato PDF e inseridas no software Atlas $T i^{2}$, recebendo,

2 O software Atlas Ti foi adquirido na versão Mac para a análise qualitativa dos dados textuais, o software permite que a análise ocorra em gráficos, áudios e vídeos. O Atlas Ti possui ferramentas que ajudam na organização, sistematização e no gerenciamento dos dados. Possibilita a descoberta de fenômenos complexos, os quais, possivelmente, não seriam detectáveis por meio de uma simples leitura do texto e do tratamento manual dos dados. 
por conseguinte, um código para cada pesquisa, preservando seu anonimato. Desta forma, as dissertações receberam o código (D) e as teses (T), seguidas de um número correspondente ao autor de cada pesquisa, como, por exemplo, D01 - Dissertação do autor 01. Todas os códigos elaborados foram registrados em uma planilha de Excel, contendo: título, autor e ano da pesquisa.

Fase 2 - Exploração do material: As seções das considerações finais das 344 pesquisas foram selecionadas pelos pesquisadores no software Atlas Ti, com a finalidade de que essas fossem codificadas com o auxílio da referida ferramenta computacional.

Fase 3 - Codificação: Nesta etapa foram criados códigos, a fim de operacionalizar o processo de categorização. Os códigos foram representados por um sistema de símbolos que permite a identificação de informações. A posteriori, realizou-se uma leitura crítica dos trechos selecionados, criando para esses, códigos que expressam contribuições e implicações dos achados das investigações. Conforme acontecia a leitura das considerações finais das teses e dissertações, os pesquisadores utilizaram também códigos já previamente criados. Para tanto, nesta investigação foram criados 126 códigos.

Fase 4 - Categorização: Esta etapa tem como objetivo a união, ou seja, a formação de conjuntos de códigos por incidência e semelhança, ação que permite agrupar dados e consolidar um significado para tais informações. Depois que todas as considerações finais das dissertações e teses foram codificadas e categorizadas visualizou-se no software Atlas Ti os códigos que tiveram maior incidência e semelhança diante dos resultados das pesquisas analisadas.

Fase 5 - Análise de Conteúdo: Os códigos com maior incidência e semelhança foram submetidos a quatro procedimentos adicionais, por meio da Análise de Conteúdo (BARDIN, 2011), sendo esses: a) leitura detalhada dos resultados encontrados; b) análise reflexiva, por parte dos pesquisadores, dos resultados das considerações finais das pesquisas; c) identificação e criação dos grupos de categorias de 
convergência, para fins de consolidação de um significado; e d) criação de categorias de significados.

As categorias emergentes constituíram-se como indicadores, as quais possibilitaram compreender as incidências semelhantes presentes nas e entre as considerações finais das dissertações e teses selecionadas para o presente estudo, permitindo aos pesquisadores visualizar o estado da arte da pesquisa científica voltada à Educação Online e à Educação Aberta no período de 1996 a 2017.

A seguir, são apresentados quadros que representam três elementos textuais identificados nas considerações finais das dissertações e teses que foram utilizados como exemplos para a criação das categorias, diante da quantidade de incidência e semelhança que um mesmo código teve. Diante da análise dos dados, o software Atlas Ti revelou 03 códigos com maior incidência e semelhança frente aos resultados analisados que abordavam os seguintes aspectos: a) a flexibilização da educação; b) a utilização de diferentes recursos didáticos e tecnológicos; e c) a dificuldade para manter a motivação dos participantes.

Como mencionado, um dos códigos que apresentou incidência e semelhança nas considerações finais das teses e dissertações foi "flexibilização da educação", com 251 incidências. Conforme o Quadro 1, apresenta-se as categorias que foram criadas a partir do código analisado.

Quadro 1 - Alguns resultados explicitados nas pesquisas para justificar o código flexibilização da Educação

(continua)

\begin{tabular}{|l|c|}
\hline \multicolumn{1}{|c|}{ CATEGORIAS } & TESE E DISSERTAÇÃO \\
\hline \multicolumn{1}{|c|}{ Diante do Ensino } & $\begin{array}{c}\text { Quantidade de incidência } \\
\text { que o código teve: } 95\end{array}$ \\
\hline $\begin{array}{l}\text { "Na pesquisa realizada os professores tutores enfatizaram na } \\
\text { entrevista que a flexibilização da educação a distância trouxe } \\
\text { grandes contribuições para que o tutor pudesse planejar e } \\
\text { direcionar o processo de ensino". }\end{array}$ & T77 \\
\hline $\begin{array}{l}\text { "A flexibilização da educação online permite contribuições } \\
\text { que vão além da mediação pedagógica, o professor consegue } \\
\text { estruturar o processo de ensino diante do ritmo de aprendizagem } \\
\text { do aluno, por meio de um planejamento de ensino mais } \\
\text { conveniente para a aprendizagem do aluno ". }\end{array}$ & D192 \\
\hline
\end{tabular}

Rev. Diálogo Educ., Curitiba, v. 19, n. 60, p. 14-35, jan./mar. 2019 


\begin{tabular}{|c|c|}
\hline $\begin{array}{l}\text { "Na educação aberta a flexibilização do ensino propicia vantagens } \\
\text { significativa para que o professor possa ensinar de uma maneira } \\
\text { mais ativa diante da colaboração dos alunos". }\end{array}$ & D213 \\
\hline Diante da Aprendizagem & $\begin{array}{l}\text { Quantidade de incidência } \\
\text { que o código teve: } 156\end{array}$ \\
\hline $\begin{array}{l}\text { "Um indicador que apareceu com bastante recorrência nas } \\
\text { respostas dos alunos foi que a flexibilização da educação aberta } \\
\text { contribui para que o aluno tenha diversas oportunidades de } \\
\text { aprendizagem durante o curso". }\end{array}$ & T55 \\
\hline $\begin{array}{l}\text { "Diante da análise dos dados foi possível identificar que a } \\
\text { flexibilização da educação a distância na modalidade online } \\
\text { colaborou para que os participantes pudessem aprender de forma } \\
\text { sistêmica a temática envolvida no curso". }\end{array}$ & D199 \\
\hline $\begin{array}{l}\text { "A flexibilização dos materiais didáticos utilizados contribuiu } \\
\text { para a formação continuada online e foi fundamental para a } \\
\text { aprendizagem dos professores". }\end{array}$ & D245 \\
\hline
\end{tabular}

Fonte: Os autores.

No Quadro 1 foi possível identificar que a categoria "aprendizagem" apresentou 156 incidências para à flexibilização da educação. A flexibilização da educação é fundamental na Educação Online e na Educação Aberta, sendo um fator primordial e de diferença em relação ao ensino presencial. Os achados das pesquisas acadêmicas analisadas indicam que a flexibilização contribui para a aprendizagem dos alunos quando o curso ou a formação em questão apresenta um formato flexível, dinâmico e aberto, principalmente, na disponibilidade e na diversidade de recursos didáticos e tecnológicos.

A flexibilização refere-se às diversas possibilidades de ensino e aprendizagem que são oferecidas na Educação Online e na Educação Aberta por não ser um modelo de educação pré-determinado, embora exija organização e planejamento prévios. Foi possível identificar também que a flexibilização da educação permite que o processo de aprendizagem aconteça de forma mais colaborativa, que a formação aconteça diante da multiplicidade de ideias, de diferentes olhares sobre um mesmo aspecto e, principalmente, na autonomia para a produção de conhecimento, a partir de possibilidades de aprendizagem ofertadas durante o processo de ensino. Valente (2003), enfatiza que a flexibilização permite a adaptação 
de diferentes propósitos educacionais quando bem planejados para o processo de aprendizagem.

Para além do código anterior, outro código que revelou maior incidência e semelhança nas considerações finais das teses e dissertações refere-se à "utilização diferentes recursos didáticos e tecnológicos", com 311 incidências. No Quadro 2 são apresentadas as categorias que foram criadas a partir do código analisado.

Quadro 2 - Alguns resultados explicitados nas pesquisas para justificar o código utilização de diferentes recursos didáticos e tecnológicos

\begin{tabular}{|c|c|}
\hline CATEGORIAS & TESE E DISSERTAÇÃO \\
\hline Favorece a Interação & $\begin{array}{l}\text { Quantidade de incidência } \\
\text { que o código teve: } 33\end{array}$ \\
\hline $\begin{array}{l}\text { "Um indicador extraído nas entrevistas foi que a os diversos } \\
\text { recursos tecnológicos utilizados contribuíram para o processo de } \\
\text { interação entre professor e alunos e entre alunos". }\end{array}$ & T13 \\
\hline $\begin{array}{l}\text { "No curso aberto ofertado aos professores foi possível verificar } \\
\text { contribuições a partir da interação. O professor tutor utilizou diferentes } \\
\text { recursos didáticos e tecnológicos que foram disponibilizados no } \\
\text { processo de formação e essenciais para a interação". }\end{array}$ & D300 \\
\hline $\begin{array}{l}\text { "A interação realizada no curso online foi um elemento fundamental } \\
\text { para o sucesso do mesmo, pois favoreceu o desenvolvimento do } \\
\text { senso de equipe, a valorização e o compartilhamento dos saberes } \\
\text { individuais e a construção de um saber coletivo, bem como, a } \\
\text { utilização de diferentes recursos didáticos e tecnológicos que foram } \\
\text { essenciais para as discussões e interações que aconteceram". }\end{array}$ & D115 \\
\hline $\begin{array}{l}\text { Permite usar metodologias interativas no processo } \\
\text { de ensino e aprendizagem }\end{array}$ & $\begin{array}{l}\text { Quantidade de incidência } \\
\text { que o código teve: } 278\end{array}$ \\
\hline $\begin{array}{l}\text { "A utilização dos diversos recursos didáticos e tecnológicos } \\
\text { possibilitou uma discussão sobre a metodologia utilizada no curso } \\
\text { a partir das entrevistas realizadas que enfatizaram a importância do } \\
\text { uso de metodologias interativas no curso". }\end{array}$ & T51 \\
\hline $\begin{array}{l}\text { "Os discentes destacaram que a gamificação permitiu compreender } \\
\text { melhor o conteúdo ministrado pelo curso online a partir da } \\
\text { aprendizagem colaborativa e dos diferentes recursos didáticos e } \\
\text { tecnológicos utilizados ao longo da formação". }\end{array}$ & D275 \\
\hline $\begin{array}{l}\text { "Outro item que aparece em destaque na fala dos sujeitos } \\
\text { investigados foi que os recursos didáticos e tecnológicos, bem } \\
\text { como a construção coletiva do REA possibilitou o conhecimento de } \\
\text { diferentes metodologias interativas para a educação a distância". }\end{array}$ & D66 \\
\hline
\end{tabular}

Fonte: Os autores.

Rev. Diálogo Educ., Curitiba, v. 19, n. 60, p. 14-35, jan./mar. 2019 
No Quadro 2 foi possível identificar que a categoria "metodologias interativas no processo de ensino e aprendizagem" apresentou 278 incidências a partir dos conteúdos das considerações finais que envolviam Educação Online e Aberta. Infere-se assim que o número de incidência reforça a importância da utilização de recursos didáticos e tecnológicos e sua contribuição para a aplicação de metodologias interativas no processo de ensino e aprendizagem. Desta forma, foi possível identificar nessa categoria que as metodologias interativas são importantes para o formato da Educação Online e Aberta, pois elas possibilitam que os alunos se envolvam mais no processo de aprendizagem, de forma a ter interesse em pesquisar e entender o que foi discutido. Nas metodologias interativas, o professor centraliza e problematiza questões para desenvolver competências ligadas à postura investigadora, crítica e na busca de soluções criativas (TORI, 2015). A aprendizagem baseada em problemas e os estudos de caso são exemplos de metodologias interativas que podem contribuir significativamente com o processo de ensino e aprendizagem. No entanto, o professor precisa conhecer bem as características das metodologias para utilizá-las na educação a distância.

No Quadro 3, o código "dificuldade para manter a motivação dos participantes" apresentou 306 incidências diante das considerações finais das teses e dissertações como uma dificuldade presente para a Educação Online e Educação Aberta. Conforme o Quadro 3, apresenta-se as categorias que foram criadas a partir do código analisado.

Quadro 3 - Alguns resultados explicitados nas pesquisas para justificar o código dificuldade para manter a motivação dos participantes

(continua)

\begin{tabular}{|l|c|}
\hline \multicolumn{1}{|c|}{ CATEGORIAS } & $\begin{array}{c}\text { TESE E } \\
\text { DISSERTAÇÃO }\end{array}$ \\
\hline \multicolumn{1}{|c|}{ Por causa da metodologia de ensino utilizada } & $\begin{array}{c}\text { Quantidade de } \\
\text { incidência que o código } \\
\text { teve: } \mathbf{2 3 1}\end{array}$ \\
\hline $\begin{array}{l}\text { "O curso online apresentou dificuldades para manter a motivação } \\
\text { dos participantes, pois a análise dos dados revelou que a proposta } \\
\text { metodológica utilizada não atendia os interesses dos alunos diante da } \\
\text { aprendizagem que os mesmos procuravam". }\end{array}$ & T71 \\
\hline
\end{tabular}


(conclusão)

\begin{tabular}{|l|c|}
\hline $\begin{array}{l}\text { "Como implicação ao curso aberto, a falta de motivação foi um item } \\
\text { presente nas respostas do questionário online. A análise dos dados } \\
\text { possibilitou identificar que a desmotivação aconteceu porque a } \\
\text { metodologia do curso não era atrativa, dinâmica e flexível". }\end{array}$ & D08 \\
\hline $\begin{array}{l}\text { "Um problema detectado na entrevista com os professores foi a } \\
\text { desmotivação para continuar a formação continuada, os mesmos } \\
\text { alegaram que a metodologia utilizada era a mesma para todos os } \\
\text { módulos estudados". }\end{array}$ & D256 \\
\hline \multicolumn{1}{|c|}{ Por causa do professor-tutor } & $\begin{array}{c}\text { Quantidade de } \\
\text { incidência que o código } \\
\text { teve: 75 }\end{array}$ \\
\hline $\begin{array}{l}\text { Os discentes se sentiram desmotivados, pois o professor-tutor não } \\
\text { sanava as principais dúvidas apresentadas pelos alunos". }\end{array}$ & T51 \\
\hline $\begin{array}{l}\text { "Pelo relato dos participantes, os mesmos se sentiram desmotivados } \\
\text { para realizar as atividades propostas, pois o professor tinha sempre } \\
\text { respostas prontas e iguais para responder os participantes". }\end{array}$ & D275 \\
\hline $\begin{array}{l}\text { "Na observação participante eu como pesquisador pude perceber que } \\
\text { os alunos ficaram desmotivados para realizar o curso online pois o } \\
\text { professor-tutor não realizava uma mediação pedagógica adequada, o } \\
\text { mesmo tinha dificuldade para se comunicar e exemplificar os assuntos } \\
\text { tratados no curso". }\end{array}$ & D66 \\
\hline
\end{tabular}

Fonte: Os autores.

No Quadro 3 foi possível identificar que a categoria "metodologia de ensino" apresentou 231 incidências. Os resultados das pesquisas acadêmicas evidenciaram que a dificuldade para manter a motivação do aluno parte de uma metodologia de ensino que não atende às necessidades de aprendizagem, bem como o interesse do aluno em aprender determinado assunto. Uma formação específica para atuar como professor na educação a distância é essencial para exercer a docência. Sem formação e conhecimentos pedagógicos específicos das características da Educação a Distância, o docente terá dificuldades para mediar o processo de ensino e aprendizagem, bem como, para interagir e motivar os alunos para aprender e produzir conhecimentos (SILVA, 2012).

\section{Considerações finais}

Este artigo teve como objetivo mapear e analisar as contribuições e implicações das pesquisas científicas, dissertações e teses, durante 
o período de 1996 a 2017 com vistas a compreender melhor o que essas investigações têm revelado sobre Educação Online e Educação Aberta.

A partir das categorias que emergiram das considerações finais das teses e dissertações foi possível identificar contribuições da flexibilização da educação para a aprendizagem diante da Educação Online e Educação Aberta, sendo que a flexibilização contribui para: a escolha de horários mais convenientes para estudar; possibilita que o aluno organize e realize seu próprio ritmo de aprendizado; a escolher o melhor local e horário para estudar; utilizar os mais diversos recursos didáticos e tecnológicos disponíveis pela plataforma de estudo e acessibilidade ao conhecimento aberto e móvel.

A flexibilização permite progresso para a educação a distância, sobretudo, no contexto da Educação Online e Educação Aberta, pois quanto mais flexível for o formato de ensino, mais serão as possibilidades de aprendizagem para os alunos, pois os mesmos aprendem de formas diferentes, utilizando diversos recursos tecnológicos para estudar, interagir, comunicar e, principalmente, aprender e construir conhecimentos úteis para a vida pessoal e profissional.

Identificou-se também, a partir da análise dos dados, que a utilização de recursos didáticos e tecnológicos na Educação Online e Aberta contribui para a utilização de metodologias interativas no processo de ensino e aprendizagem. Com isso, infere-se que o progresso da sociedade permite que novos conhecimentos teóricos e práticos sejam colocados à disposição da Educação, como diversos recursos didáticos e tecnológicos que surgem na contemporaneidade para ensinar e aprender. As pesquisas das teses e dissertações apontaram para uma diversidade de recursos didáticos e tecnológicos utilizados em escolas, na formação de professores, em cursos abertos e Online.

As pesquisas mencionam a utilização das mais diversas mídias como recurso didático e tecnológico entre as quais podemos mencionar: as redes sociais, ambiente em realidade virtual para usuários da educação a distância, realidade aumentada, robótica, laboratórios virtuais, recursos educacionais abertos, repositórios, entre outras. Em relação às 
metodologias de ensino, as pesquisas elucidaram a utilização das seguintes metodologias: sala de aula invertida, gamificação, simulações de práticas em laboratórios e outras metodologias ativas.

A Educação Online e a Educação Aberta possibilitam que modificações ocorram no processo de ensino e aprendizagem a partir de metodologias que proporcionem um ensino personalizado e aberto para diferentes formas de aprendizagem e que propicie o acesso e a permanência à educação. Os recursos didáticos e tecnológicos contribuem para a utilização de metodologias interativas, pois estes permitem dinamizar o ensino para a construção de conhecimento baseada na interação e na relação de diferentes saberes sobre um ponto de vista.

Os dados da pesquisa revelaram também que a Educação Online e a Aberta têm dificuldade para motivar os participantes porque as metodologias de ensino utilizadas não atendem às exigências e expectativas dos alunos, bem como o perfil dos discentes. A desmotivação é um item muito recorrente na educação a distância, as pesquisas das teses e dissertações revelaram que a desmotivação é maior na Educação Aberta e neste formato a evasão é grande em relação a Educação Online.

Metodologias de ensino ineficientes não geram aprendizagem em nenhum formato de Educação, portanto é fundamental que a metodologia de ensino esteja atrelada ao perfil de diferentes formas de aprendizagem, em que os discentes sejam participantes ativos e responsáveis também pela aprendizagem. A investigação que ocorreu a partir do mapeamento e da análise dos dados que ocorreu nas considerações finais das pesquisas acadêmicas permitiu que os pesquisadores apontassem avanços e lacunas em relação à Educação Online e à Aberta.

As investigações apontam que os avanços na educação a distância derivam da associação das tecnologias com as metodologias interativas, onde essa convergência resulta na possibilidade de tornar a aprendizagem mais significativa e criativa. O professor tem um papel fundamental na organização, no planejamento, na interação e na mediação pedagógica a partir da escolha da metodologia de ensino e das tecnologias utilizadas. As metodologias interativas utilizadas na Educação Online e na Educação 
Aberta possibilitam que o aprendizado aconteça a partir de problemas e situações reais, da personalização do ensino com característica colaborativa, autônoma e disruptiva.

Enquanto lacunas, as investigações no contexto da Educação Aberta ainda são em menor número, principalmente no quesito da democratização deste formato de Educação a partir da criação de recursos educacionais abertos. Os desafios em torno da Educação Online e da Educação Aberta estão direcionados a partir da dificuldade de democratização desses dois formatos de Educação a Distância e da utilização de diferentes metodologias de ensino, principalmente as metodologias ativas, em plataformas ou ambientes virtuais de aprendizagem que utilizam uma variedade de tecnologias. Em pesquisas futuras pretende-se, a partir do escopo deste estudo, investigar a utilização de diferentes metodologias, entre elas, as metodologias ativas na Educação Online Aberta.

\section{Referências}

AIRES, L. E-learning, Educação Online e Educação Aberta: contributos para uma reflexão teórica. Rede Iberoamericana de Educação a Distância - RIED, Madri, v. 1, n. 19, p. 253-269. 2016. Disponível em: <http://revistas.uned.es/index.php/ ried/article/view/14356>. Acesso em: 04 jan. 2019.

BARDIN, L. Análise de Conteúdo. São Paulo: Edições 70, 2011.

BRASIL. Lei de Diretrizes e Bases da Educação Nacional. Lei no 9.394, de 20 de Dezembro de 1996. Estabelece as diretrizes e bases da educação nacional. Diário Oficial da União, Brasília, DF, 23 dez. 1996. Disponível em: <http://www.planalto. gov.br/ccivil03/leis/19394 >. Acesso em: 30 dez. 2018.

KEARSLEY, G. Educação Online: aprendendo e ensinando. São Paulo: Cengage Learning, 2011. 
MORAN, J. M. Contribuições para uma Pedagogia da Educação Online. In: SILVA, M (Org.). Educação Online: teorias, práticas, legislação e formação corporativa. 4. ed. São Paulo: Edições Loyola, 2012. p. 41-52.

MOTA, R; FILHO, H. C; CASSIANO, W. S. Universidade Aberta do Brasil: democratização do acesso à educação superior pela rede pública de educação a distância. In: Desafios da Educação a Distância na Formação de Professores. Brasília: Secretaria de Educação a Distância, Ministério da Educação, 2009. p. 13-26.

OKADA, A. Aprendizagem aberta e estratégias de webconferência. Revista CoLearn, Projeto OpenLearn. v. 1, n. 1, p. 01-16, nov. 2009. Disponível em: <http://labspace.open.ac.uk/journal>. Acesso em: 04 jan. 2019.

ROMANOWSKI, J. P; ENS, R. T. As pesquisas denominadas do tipo "estado da arte" em educação. Revista Diálogo Educacional, Curitiba, v. 6, n. 19, p. 3750, set./dez. 2006. Disponível em: <https://periodicos.pucpr.br/index.php/ dialogoeducacional/article/view/24176/22872>. Acesso em: 30 dez. 2018.

SANTOS, E. Educação Online para além da EAD: um fenômeno da cibercultura. In: Actas do Congresso Internacional Galego-Português de Psicopedagogia, 10, 2009, Braga. Anais... Braga: Universidade do Minho, 2009. p. 5658-5671. Disponível em: <http://www.educacion.udc.es/grupos/gipdae/documentos/ congreso/Xcongreso/pdfs/t12/t12c427.pdf>. Acesso em: 04 jan. 2019.

SILVA, M. Educação Online: teorias, práticas, legislação, formação corporativa. 2. ed. São Paulo: Edições Loyola, 2009.

SILVA, M. Formação de Professores para a Docência Online. São Paulo: Edições Loyola, 2012.

TORI, R. Tecnologia e metodologia para uma educação sem distância. Em rede: revista de Educação a distância, São Paulo, 2015, v. 2, n. 2, p. 44-55. 2015. Disponível em: <http://aunirede.org.br/revista_2.4.8-2/index.php/emrede/ article/viewFile/64/82>. Acesso em: 03. Jan. 2019. 
VALENTE, J.A. Educação a distância no ensino superior: soluções e flexibilizações. Revista Interface, São Paulo, v. 7, n. 12, p.139-148, fev. 2003. Disponível em: <http://www.scielo.br/pdf/icse/v7n12/v7n12a09.pdf〉. Acesso em: 02 jan. 2019. VOSGERAU, D. S. R.; ROMANOWSKI, J. P. Estudos de Revisão: implicações conceituais e metodológicas. Diálogo Educacional, Curitiba, v. 14, n. 41, p. 165-189, jan/abr. 2014. Disponível em: <https://periodicos.pucpr.br/dialogoeducacional/ article/>. Acesso em: 04 jan. 2019.

Recebido: 05/01/2019

Received: 01/05/2019

Aprovado: 02/02/2019 Approved: 02/02/2019 